\title{
Innovation and Value: Customer Perception, Application, and Concept
}

\author{
Owen O. Roach ${ }^{*}$, Gregory C. McLaughlin ${ }^{* *}$ and Heidi M. McLaughlin ${ }^{* * *}$
}

\begin{abstract}
This research aims to understand, quantify how individuals perceive the meaning of the word Innovation, and its overall value. The study builds on research conducted in 2012 (Caraballo \& McLaughlin), which examined a specific and relatively homogenous socio-cultural group (Hispanic IT Professionals pursuing further educational advancement). In the previous study, there was a definitive difference between generational cohorts in perceiving innovation. This updated study selects a group of MBA students from a culturally diverse group to determine if the differences remain between generational cohorts. A traditional definition of innovation generally refers to the creation of a new or novel product or service. This study intends to demonstrate that a more general sample might perceive similar generational differences in perceiving the definition and Value of Innovation. The research identifies innovation as having three constructs: new, improved, or change (Zhuang, 1999). This paper confirmed earlier findings (Caraballo \& McLaughlin, 2012), which redefined innovation as a multi-dimensional construct. The 2019 research was able to demonstrate differences between those with and without a technical background. The findings further complicate those marketing and sales efforts to this diverse population.
\end{abstract}

Keywords: Innovation, Generations, Definition, Application, Customer Value

\section{INTRODUCTION}

The Value of Innovation is generational dependent. Customers concept and perspective of value fall into three categories (Bowersox, Closs, Cooper, \& Bowersox):

1) Economic value; derived from the traditional operational economies of scale, which emphasizes efficiency in creating products and services.

2) Market Value; emphasizes available products or services that satisfy the customers' needs, and effective delivery at the right place and time.

3) Relevancy Value; a combination of economic and market value integrated with customization of products and services, segmental diversity, product or service positioning in the supply chain (2013).

*Saint Leo University, Florida, USA E-mail: owen.roach@saintleo.edu

*** Park University, Missouri, USA E-mail: gregory.mclaughlin02@park.edu

${ }^{* * *}$ Park University, Missouri, USA E-mail: heidi.mclaughlin@park.edu 
Innovation is a critical need for all organizations as it adds organizational value, sustains competitive advantage (Baregheh, Rowley, \& Sambrook, 2009, p.1323), and expands the growth opportunities. A need exists for organizations to innovate (McLaughlin, McLaughlin \& Preziosi, 2004) as well as a principal source of wealth creation (de Waal, Maritz, \& Shieh, 2010), and become value innovators (Kim \& Mauborgne, 1997). It is essential to involve personnel in innovation projects for both competitive advantage and their human perspective, as ideas and especially needs drive innovation, leading to creating value for its customers. Competitive businesses should pursue clear innovative strategies and value principles that reflect the firm's cultural values (Subbotina, 2015: Kim \& Mauborgne, 1997). Through collaboration, value innovators should allow customers to be at the forefront of the innovation process (Kowalkowski, 2011). Innovation is not just confined to often thought of as confined to developed. Multinational corporate leaders for companies such as Toyota, Honda, Starbucks, Apple, and Procter and Gamble generated growth and profit by integrating innovation as a core value proposition into their corporations' corporate culture, operational, and organizational strategies (Prahalad, 2012). Innovation is globally recognized and is integral to the development and progress of emerging economies. No one country has a "hold" or "lead" in innovation.

The concept of innovation extends from ideas/concepts to products, processes, and services. Innovative companies can alleviate market risks, develop sustainable strategies, position the organization to accomplish long term growth, align its organizational culture (Kumar, 2014), and create customer value. Innovation is not just about new technology; it begins with a need, wants, or desire. People accept that need and resulting innovation differently depending upon how they define innovation. Value innovation is the approach that an organization can take to establish standards, which are different from competitors, and offer customers a proposal that has the possibility of being an appreciated commodity (Kim \& Mauborgne, 1997; Vargo \& Lusch, 2008).

\section{DEFINITION OF INNOVATION}

Given its critical function, innovation should be a readily identified concept that has a generally accepted definition. Flight, Allaway, Kim, and D'Souza (2011) state that the ability to measure how individuals perceive innovation is essential for identifying problems related to success. Baregheh et al. (2009) identified over 60 different definitions of innovation collected from management, economics, technology, knowledge management, and marketing.

Historically, Thompson (1965, p. 2) defined innovation as "the generation, acceptance, and implementation of new ideas, processes, products, and services." A more recent definition by Wang, et al., states that innovation is "conceptually a process beginning with an original idea and concludes with a market introduction" $(2010$, p. 767). Therefore, one should consider innovation as commencing with the new idea and ending with a commercial product/service. A characterization of innovation is a radical change and incremental improvement of products/services and processes (The Conference Board of Canada, 2019). Instead, innovation is more than a wide variation; it involves technology, new operating methods, and new management paradigms. According to Baregheh et al. (2009), definitions of innovation today contain elements that overlap and often seem contradictory. Overlapping leads to "a situation in which there is no clear and authoritative definition of innovation" (Baregheh et al., 2009, p. 1324).

Therefore, innovation must be

1) Examined from the point of origin;

2) Involve a transformation of some kind; and

3) Meet a need that satisfies the customer. 
In general, innovation begins when humans use a creative or rational process to meet a particular need; therefore, innovation begins at a very human level. In order to clarify a definition of innovation that will relate to an individual, the authors decided to examine the "means of innovation" (Baregheh et al., 2009, p. 1334); that is, understanding how innovation "transforms ideas into new, improved or changed entities" (Baregheh et al., 2009, p. 1334). This understanding brings innovation to an individual perspective. Innovation is often a response to consumers' purchasing habits that meet their needs. Finally, a group of innovation experts, when asked to define innovation, highlighted the following descriptors:

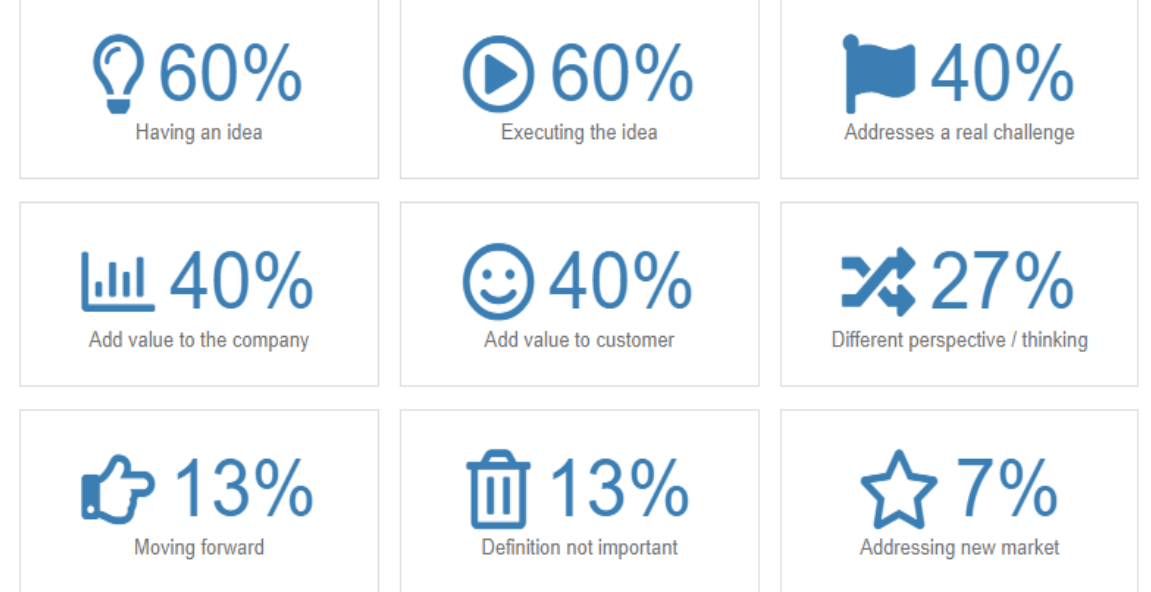

Figure 1: Keywords describing innovation Adapted from (Skillicorn, N. (2016).

Innovation is a multi-faceted process, not a single or discrete act (Baregheh et al., 2009, p. 1334) involving people, processes, and technology. An understanding of innovation should be definitive as to the need and intent of the desired outcome. Innovation as a multi-faceted, multidimensional set of characteristics precludes a "one size fits all" approach. Innovation is outcome dependent (Zhuang, 1995), and this is reflected in the definition. That is, the desired outcome (for example, a new technology) generates its definition. The desired outcome is a response factor based on the demands of individuals (Matwiejczuk, 2013). The driving force at the epicenter of the innovative process is the individual's demands for goods or services. Therefore, searching for a more unified approach to understanding innovation begins with the individual.

An individual's ability to innovate relies on skill sets, knowledge, and a positive attitude (Zhuang, 1995, p. 15). They bring together these characteristics to initialize the innovation process. Zhuang (1995) created a 10-item survey that measured how individuals understand innovation; what innovation means to an individual. Individuals evaluated each conceptual statement of innovation with their level of agreement or disagreement using a five-point Likert scale. A comparison of average responses for each question resulted in no statistical differences (Zhuang, 1995). Zhuang did encounter a diversity of responses, as exhibited in his pilot study (1995), causing the averages to test as insignificant. Zhuang (1995) found that the 10 statement means responses were indistinguishable. However, Zhuang did not pursue any further and more sophisticated analysis.

In the 2014 study, Zhuang's survey was slightly modified (with his permission) and included examining a Factor Analysis in determining the survey question alignment. At times, the definition was less clear, and a distinctive "new," "improve," and change/replacement" element was group tested.

Previous research with like cultural groups (US Hispanics IT Professionals, South American IT Professional, Nurse Professionals, Chinese businesspeople) also demonstrate generational 
differences (Caraballo \& McLaughlin, 2014; McLaughlin \& Richins, 2015; Unpublished Work, 2016). The test result in all groups revealed a difference between the three generations, and the results were more similar than different. The authors will, in this new study, in which culture is not considered a limiting factor, attempt to answer the following research questions:

1. To what extent does an individual perception of innovation continue to vary between generations?

2. What is the difference between an individual perception of individual perceptions of innovation across demographic categorizations of gender or experience level?

3. Does the concept of Value (a new measure) change for differing generations?

\section{CONCEPT OF VALUE}

Companies gained a competitive advantage by responding to customers' demands (Fawcett, Wallin, Allred, Fawcett, \& Magnan, 2011; Matwiejczuk, 2013) for product or service an intrinsic set of values to the purchaser (individual). Value is the combination of the customer's perception and utility experienced from using a product or service (Buttle, \& Maklan, 2019; Simchi-Levi, Kaminsky, Simchi-Levi, \& Shankar, 2008). Value innovation is the motivation of an individual or firm to create a theoretically appreciated product or service to users (Chesbrough, Lettl, \& Ritter, 2018) with a unique set of appeals. The unique set of appeals should encompass the characteristics of the customers' perspective - economic value, market value, and relevancy value. Businesses that understand the customers' needs factors can provide innovative solutions to complex problems in a continuously changing society. The marketing of a product or service to clientele is not a delivered value but a value proposition capable of being appreciated by the customer (Vargo \& Lusch, 2008).

The value concept is not simply because it involves a detailed analysis of customer value dimensions. Companies should decide on the attributes that distinguish them from the competition. Taking into account the five distinct dimensions (Simchi-Levi et al., 2008) and the customer-centric values (Seybold et al., 2001), an analysis of the competitive advantage for the company grounded in price, product, service, access, and relationships is the fundamental principle on which a business should decide their competitive advantage (Crawford \& Mathews, 2007). The possibility of competing on all fronts is impossible.

\section{BUSINESS MODEL INNOVATION}

Business model innovation (BMI) involves designing an acceptable business concept with different capabilities of creating novel products and services that represent a new constituent for the company, which individuals will perceive as innovative (Massa \& Tucci, 2013). Dell's "build your system in three easy steps" is an individual's perception of the users' ideal computer system and logistics distribution network. Companies increase product value to the customers through innovation and create new value offerings for the firm, resulting in an increased revenue stream to the firm (Matzler, Bailom, Friedrich von, \& Kohler, 2013).

Within the BMI, value innovators focus on the customer, creates a product or service that the customer perceives as valuable (Kim \& Maubourge, 1997). The innovative value of a product or service is the perspicacity of how an individual value the utility of the company's offering. The Value of Innovation means moving beyond industry space; it is a revolutionary process in the individual (Kim, 2005) that a product or service is new and creates value. The individual perception of innovation is examined and understood differently based on cultural exposure to information, communication and technological advances, investment in research and development (R\&D), and organizational developmental stages (Kumar, 2012). 
Cultural dimensions, which help inform innovation, contain personal traits that are individualistic and confine to set principles across global boundaries (Wang, Guidice, Tansky, \& Wang, 2010). Innovation is a significant driver for long-term corporate growth. However, corporate leaders should possess the knowledge and confidence to move beyond the comfort zone of the organization's status quo to benefit from Innovation (Buisson \& Silberzahn, 2010), ultimately satisfying the customers' needs.

Companies that respond to customers' demands demonstrate a willingness to adapt and develop products or services that consumers value. Innovation is paramount to the success of large or small companies. The Value of Innovation cannot be overemphasized as companies continue to spend on research and development (R\&D), which is integral to innovation. According to Wang, Guidice, Tansky, and Wang (2010), "in the midst of a global economic recession, Booze and Company's Global Innovation 1000 report indicates that more than two-thirds of firms studied maintained or increased their R\&D spending in 2008," (2008, pg. 768). An essential contribution to the value stream and profitability of an organization is the creative input of customers. Improvement in Intuit and Procter \& Gamble innovation value chain is, in part, a result of external ideas (Hansen \& Birkinshaw, 2007).

\section{BUSINESS FOCUS}

For companies to create value, management must be customer focus. Conventional strategic logic differs significantly along the line of strategy from value innovation. Value innovators do not take the circumstances around them as given; they look for and go for big ideas the - Blue Ocean Strategy (Mauborgne et al., 2004). Businesses should avoid direct competition by moving swiftly to develop new products; surrender when directly attacked by competitors; and use size and strength against competitors (Kwak, Yoffie, \& Kwak, 2001). The conventional strategy of companies offering customers what they have instead of what the customers need opens the door for disruptive innovation. Complicating the decision making for firms is the client's sophistication. The Blue ocean strategy involves R\&D intended at finding out the customer's need factors.

To advance the business position, managers need to focus on the customer. Resources need to be freed from committing to what no longer contributes to performance or produces results (Drucker, 1999) appreciated by the customer. Executives that do not emphasize customer value are unlikely to deliver superior customer value. Supply chain managers, for example, should be able to show measurable results and improving the performance of strategy-critical value chain activities that benefit the organization and, ultimately, the customer (Thompson, Strickland, \& Gamble, 2015).

Value innovators theory, as presented, is an aggressive way of operating a business to avoid stagnation. While covering most aspects of appropriate business strategies, the theory can lose a valuable customer base. The business concentration model must take customer values seriously. Customer value should be the foundation of the organization's culture and core standards. There are always possibilities for disruption within applying blue ocean strategy, especially breaking into fields with new technology. Value innovators challenge the status quo by offering improved benefits and reducing customer incidentals (Buttle, \& Maklan, 2019).

\section{ADVANCING THE RESEARCH}

This new research is both replication and expansion of previous (2013 and 2014) work. The authors continue to examine the perceptions of innovation and innovation value, but this time, most respondents are non-technical, MBA students. The reasons for choosing this group: 1) are; 
(1) to examine if there is a similarity in a less homogeneous group, and (2) to examine if perceptions have changed over the last 5-6 years.

This study explores a possible understanding of innovation generated from an individual's perception and value, based on their status as an MBA student, generational cohort differences or similarities, and a technical versus non-technical background similarly perceive innovation for the generational perspective.

\section{SELECTION OF SAMPLE}

This research's goal and objective were to recruit a heterogeneous group to determine if innovation and innovation value's perceptions have relevance in 2019. MBA students are a preferred sampling group for professional and business research. The targeted sample consisted of MBA students pursuing business studies in several diverse Universities. Students were contacted by e-mail, which encourages them to participate in the survey. Participation in the survey was voluntary, and the sample was considered random. The goal and objective are to determine if there are changes in innovation perceptions and any generational differences from previously observed groups. One hundred fifty-one respondents participated with 149 surveys useable for the analysis.

\section{STATISTICAL ANALYSIS}

In providing some context to the results, a comparison will be made between the present study (conducted in 2019) with a study completed in 2014 using the same primary instrument. The 2014 study results are published in the text, Unlocking Sustained Innovation Success in Healthcare by Mclaughlin and Richins. The contrast between studies will assist in better understanding the results.

\section{Survey Instrument (Innovation Perceptions)}

There is a slight modification to the Zhuang survey (changing two words) (Appendix A) for more straightforward use. The survey was field-tested for accuracy. Both SPSS 26 and Minitab 18 were used for statistical analysis. All tests used a 0.05 significance level.

Although Zhuang (1999) has documented that the instrument's validity and reliability, the authors ran a Factor Analysis for validity and Cronbach alpha for reliability. There are three critical assumptions for Factor analysis: (a) normality of the data, (b) linearity, and (c) conceptual linkages (Hair et al., 1995). The essential assumption is that a conceptual linkage exists, which the statistical analysis confirmed. $68 \%$ of the total variation explained (versus $65 \%$ previously with a three-factor solution) is an improvement from the 2014 study of 253 AONE (Association of Nurse Executives) participants. A Cronbach alpha of .75 (versus .79 previously) is slightly decreased due to the smaller sample size and less homogeneous group. The most significant difference is that the AONE survey identified three factors (new, improved, and changed - Figure 4), while the 2019 survey confirmed only the new dimension clearly with a four-factor solution (Figure 2). Both Factor Analyses used a principal components method with Varimax rotation. 
Figure 2: Factor Analysis Solution for Perceptions of Innovation Survey - 2019 Survey

\begin{tabular}{|c|c|c|c|c|c|c|c|c|c|}
\hline \multicolumn{10}{|c|}{ Total Variance Explained } \\
\hline \multirow[b]{2}{*}{ Component } & \multirow[b]{2}{*}{ Total } & \multicolumn{2}{|c|}{ Initial Eigenvalues } & \multicolumn{3}{|c|}{ Extraction Sums of Squared Loadings } & \multicolumn{3}{|c|}{ Rotation Sums of Squared Loadings } \\
\hline & & $\%$ of Variance & Cumulative \% & Total & $\%$ of Variance & Cumulative \% & Total & $\%$ of Variance & Cumulative $\%$ \\
\hline 1 & 3.285 & 32.848 & 32.848 & 3.285 & 32.848 & 32.848 & 2.436 & 24.355 & 24.355 \\
\hline 2 & 1.267 & 12.667 & 45.515 & 1.267 & 12.667 & 45.515 & 1.737 & 17.365 & 41.721 \\
\hline 3 & 1.114 & 11.144 & 56.660 & 1.114 & 11.144 & 56.660 & 1.367 & 13.668 & 55.389 \\
\hline 4 & 1.082 & 10.821 & 67.481 & 1.082 & 10.821 & 67.481 & 1.209 & 12.093 & 67.481 \\
\hline 5 & .785 & 7.851 & 75.332 & & & & & & \\
\hline 6 & .635 & 6.352 & 81.684 & & & & & & \\
\hline 7 & .539 & 5.391 & 87.075 & & & & & & \\
\hline 8 & .485 & 4.853 & 91.928 & & & & & & \\
\hline 9 & .460 & 4.597 & 96.525 & & & & & & \\
\hline 10 & .348 & 3.475 & 100.000 & & & & & & \\
\hline
\end{tabular}

A MANOVA (Figure 3) was conducted at the 0.05 significance level to determine the four dimensions' statistical significance and the independent variables (Age/generation, gender, and education) with only education as significant. Figure 4 is a boxplot of the 2019 scores by age, gender, and education. This chart reaffirms the statistical differences associated with education.

\section{Multivariate Tests ${ }^{\mathrm{a}}$}

\begin{tabular}{|c|c|c|c|c|c|c|}
\hline Effect & & Value & $\mathrm{F}$ & Hypothesis df & Error df & Sig. \\
\hline \multirow[t]{4}{*}{ Intercept } & Pillai's Trace & .051 & $1.725^{b}$ & 4.000 & 129.000 & .148 \\
\hline & Wilks' Lambda & .949 & $1.725^{b}$ & 4.000 & 129.000 & .148 \\
\hline & Hotelling's Trace & .053 & $1.725^{b}$ & 4.000 & 129.000 & .148 \\
\hline & Roy's Largest Root & .053 & $1.725^{b}$ & 4.000 & 129.000 & .148 \\
\hline \multirow[t]{4}{*}{ Gender } & Pillai's Trace & .023 & $.764^{b}$ & 4.000 & 129.000 & .551 \\
\hline & Wilks' Lambda & .977 & $.764^{b}$ & 4.000 & 129.000 & .551 \\
\hline & Hotelling's Trace & .024 & $.764^{b}$ & 4.000 & 129.000 & .551 \\
\hline & Roy's Largest Root & .024 & $.764^{b}$ & 4.000 & 129.000 & .551 \\
\hline \multirow[t]{4}{*}{ Age } & Pillai's Trace & .090 & 1.523 & 8.000 & 260.000 & .149 \\
\hline & Wilks' Lambda & .912 & $1.529^{b}$ & 8.000 & 258.000 & .147 \\
\hline & Hotelling's Trace & .096 & 1.535 & 8.000 & 256.000 & .145 \\
\hline & Roy's Largest Root & .082 & $2.666^{c}$ & 4.000 & 130.000 & .035 \\
\hline \multirow[t]{4}{*}{ Education } & Pillai's Trace & .229 & 2.000 & 16.000 & 528.000 & .012 \\
\hline & Wilks' Lambda & .781 & 2.078 & 16.000 & 394.739 & .009 \\
\hline & Hotelling's Trace & .268 & 2.136 & 16.000 & 510.000 & .006 \\
\hline & Roy's Largest Root & .214 & $7.076^{c}$ & 4.000 & 132.000 & .000 \\
\hline
\end{tabular}

a. Design: Intercept + Gender + Age + Education

b. Exact statistic

c. The statistic is an upper bound on $\mathrm{F}$ that yields a lower bound on the significance level.

Because the factor analysis did not yield the three innovation dimensions found in previous studies, no individual factors were analyzed. The difference between a three-factor and fourfactor solution may be due to the similarity of the participants. A three-factor solution existed only when the group shared a particular characteristic, such as technical orientation. With both the 2014 and 2019 studies, the groups contained large numbers of non-technical personnel. Innovation is recognized but not categorized into one of three groups. This result supports a large number of definitions by which innovation is described. 
Figure 4: Boxplot of independent variables and aggregate Scores.

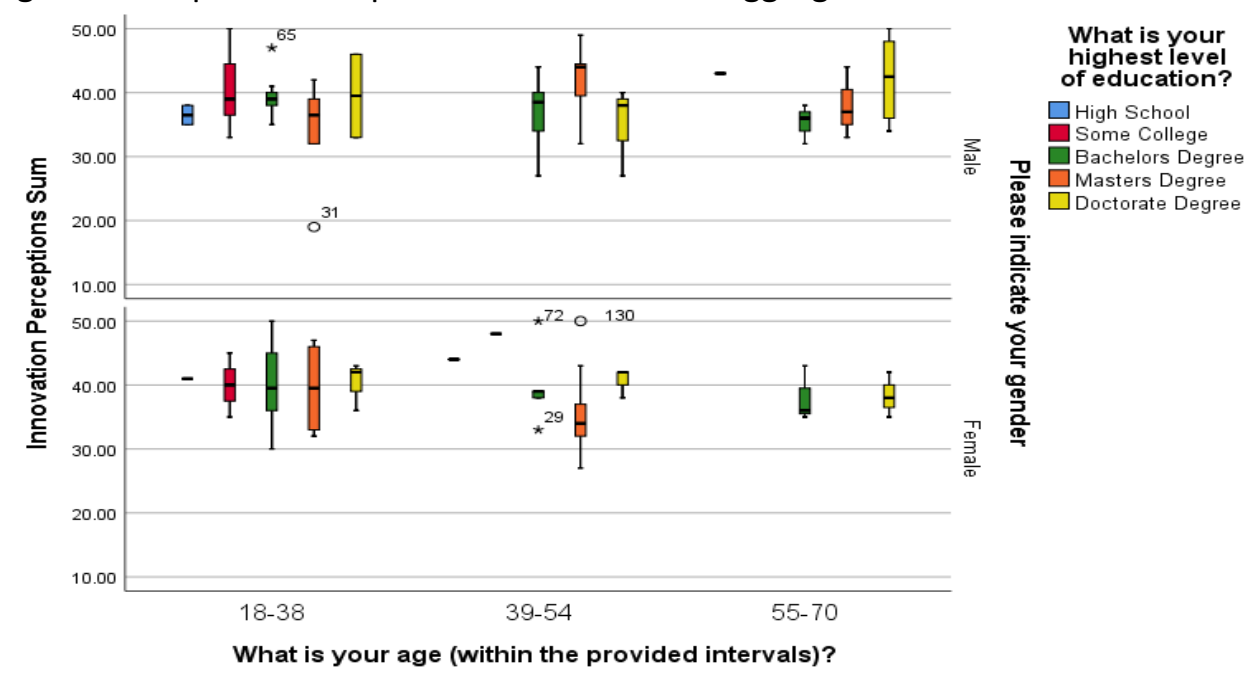

For the 2014 survey, Figure 5 displays the factor solution which excellent alignment to the three dimensions of perceived innovation. The $\%$ of variation explained is near the $70 \%$ threshold and considered acceptable.

Figure 5: Factor Loading Solution for AONE Survey conducted in 2014.

Total Variance Explained

\begin{tabular}{|c|c|c|c|c|c|c|c|c|c|}
\hline \multirow[b]{2}{*}{ Component } & \multicolumn{3}{|c|}{ Initial Eigenvalues } & \multicolumn{3}{|c|}{ Extraction Sums of Squared Loadings } & \multicolumn{3}{|c|}{ Rotation Sums of Squared Loadings } \\
\hline & Total & $\%$ of Variance & Cumulative $\%$ & Total & $\%$ of Variance & Cumulative $\%$ & Total & $\%$ of Variance & Cumulative $\%$ \\
\hline 1 & 3.834 & 38.338 & 38.338 & 3.834 & 38.338 & 38.338 & 2.330 & 23.304 & 23.304 \\
\hline 2 & 1.526 & 15.256 & 53.594 & 1.526 & 15.256 & 53.594 & 2.156 & 21.564 & 44.868 \\
\hline 3 & 1.150 & 11.497 & 65.091 & 1.150 & 11.497 & 65.091 & 2.022 & 20.223 & 65.091 \\
\hline 4 & .914 & 9.141 & 74.232 & & & & & & \\
\hline 5 & .671 & 6.709 & 80.941 & & & & & & \\
\hline 6 & .539 & 5.386 & 86.327 & & & & & & \\
\hline 7 & .439 & 4.392 & 90.719 & & & & & & \\
\hline 8 & .416 & 4.158 & 94.877 & & & & & & \\
\hline 9 & .338 & 3.379 & 98.257 & & & & & & \\
\hline 10 & .174 & 1.743 & 100.000 & & & & & & \\
\hline
\end{tabular}

In addition to the Factor Analysis, several independent variables (generation, gender, and highest degree achieved) were tested with the survey results. The most substantial factor was an improvement (i.e., highest scores). A MANOVA was used to determine which independent variables, if any, significantly contributed to defining perceptions of innovation. For the 2014 survey, generation (age group) and gender and education yielded no significant differences. There was a significant interaction between generation (age) and education (observed power $=.85$ ), which is confirmed visually with Figure 6. As with previous studies (Latino - 2012) and Asian studies (Chinese - 2016), gender differences were insignificant. In contrast, other studies (2013, 2016) have indicated a generational difference and a difference between technical and nontechnical personnel. The similarity of these Nursing Executives (all are familiar with the technology) in their perceptions of innovation was confirmed. 
Figure 6: Boxplot of Aggregate scores for ANOE 2014 Survey.

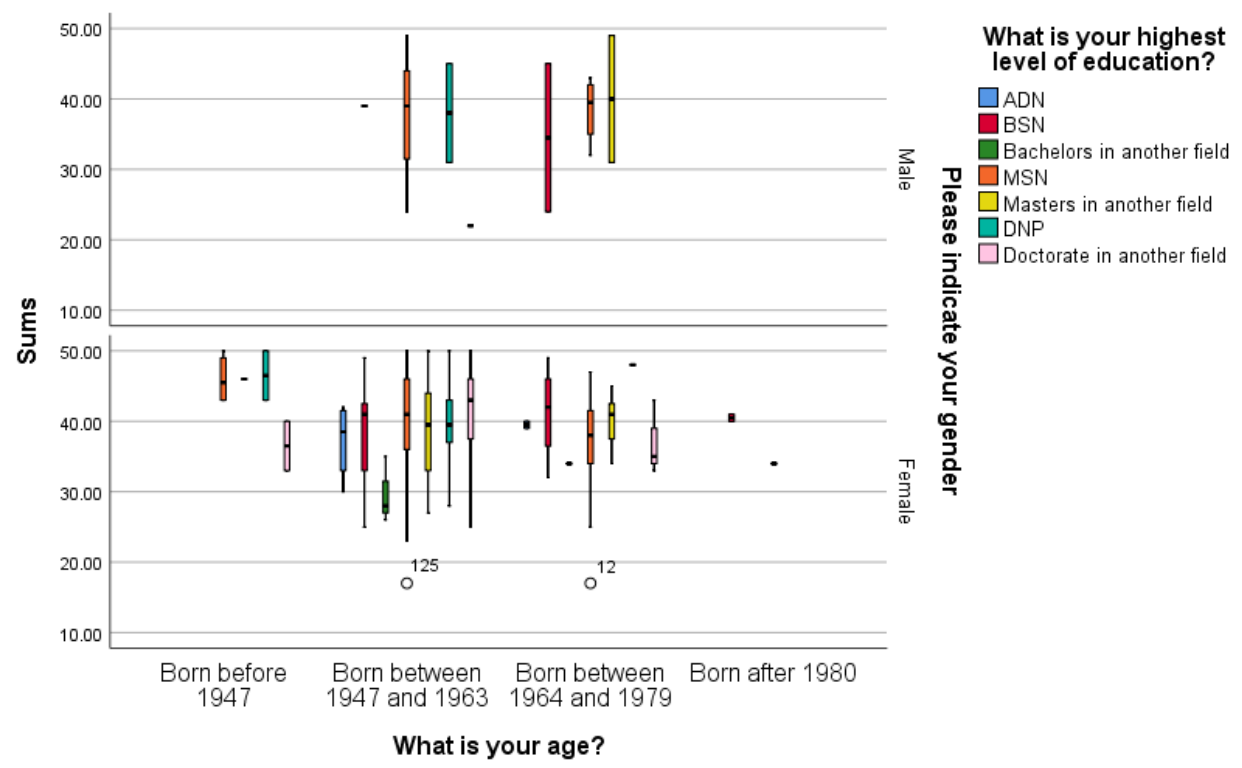

\section{Survey Instrument (Value Analysis)}

Both survey instruments are identical (Appendix B);

1) The difference is the homogeneous sample of the AONE participants and the random sample of MBA students.

2) The 2019 study provided a single factor result (Figure 7), while the 2014 study provided a 3-factor result (Figure 9).

Figure 7: Factor Analysis of MBA Students - 2019 study

\section{Total Variance Explained}

\begin{tabular}{|c|c|c|c|c|c|c|}
\hline \multirow[b]{2}{*}{ Component } & \multicolumn{3}{|c|}{ Initial Eigenvalues } & \multicolumn{3}{|c|}{ Extraction Sums of Squared Loadings } \\
\hline & Total & $\%$ of Variance & Cumulative $\%$ & Total & $\%$ of Variance & Cumulative $\%$ \\
\hline 1 & 5.041 & 72.019 & 72.019 & 5.041 & 72.019 & 72.019 \\
\hline 2 & .670 & 9.568 & 81.587 & & & \\
\hline 3 & .393 & 5.614 & 87.201 & & & \\
\hline 4 & .296 & 4.223 & 91.425 & & & \\
\hline 5 & .268 & 3.832 & 95.256 & & & \\
\hline 6 & .195 & 2.783 & 98.039 & & & \\
\hline 7 & .137 & 1.961 & 100.000 & & & \\
\hline
\end{tabular}

Over $70 \%$ of the variation is explained, indicating a valid survey. A Cronbach alpha of .95 also confirms its consistency for this group. However, there is a potential problem with Levene's test of equality of variances, with a p-value of 0.004 when testing with means, suggesting unequal variances (Figure 8). However, other tests of variance did not have a significant $p$-value. Equality of variances is a critical assumption and confirms that Likert scale responses varied greatly. 
Figure 8: Levene's Test

\begin{tabular}{|c|c|c|c|c|c|}
\hline \multicolumn{6}{|c|}{ Levene's Test of Equality of Error Variances ${ }^{a, b}$} \\
\hline & & $\begin{array}{l}\text { Levene } \\
\text { Statistic }\end{array}$ & df1 & df2 & Sig. \\
\hline \multirow[t]{4}{*}{ Sum of Value Survey } & Based on Mean & 2.265 & 19 & 117 & .004 \\
\hline & Based on Median & .898 & 19 & 117 & .586 \\
\hline & $\begin{array}{l}\text { Based on Median and } \\
\text { with adjusted df }\end{array}$ & .898 & 19 & 75.000 & .586 \\
\hline & Based on trimmed mean & 2.094 & 19 & 117 & .009 \\
\hline \multicolumn{6}{|c|}{$\begin{array}{l}\text { Tests the null hypothesis that the error variance of the dependent variable is equal across groups. } \\
\text { a. Dependent variable: Sum of Value Survey }\end{array}$} \\
\hline \multicolumn{6}{|c|}{$\begin{array}{l}\text { b. Design: Intercept }+q 0010+q 0009+q 0012+q 0010 * q 0009+q 0010 * q 0012+q 0009 * q 0012 \\
+q 0010^{*} q 0009 * q 0012\end{array}$} \\
\hline
\end{tabular}

For the 2019 data, all independent variables were tested to be non-significant. Figure 9 displays a similar median (means - data normally distributed) for all variables. The 2019 study Figure 9: Boxplot of Contributing Variables.

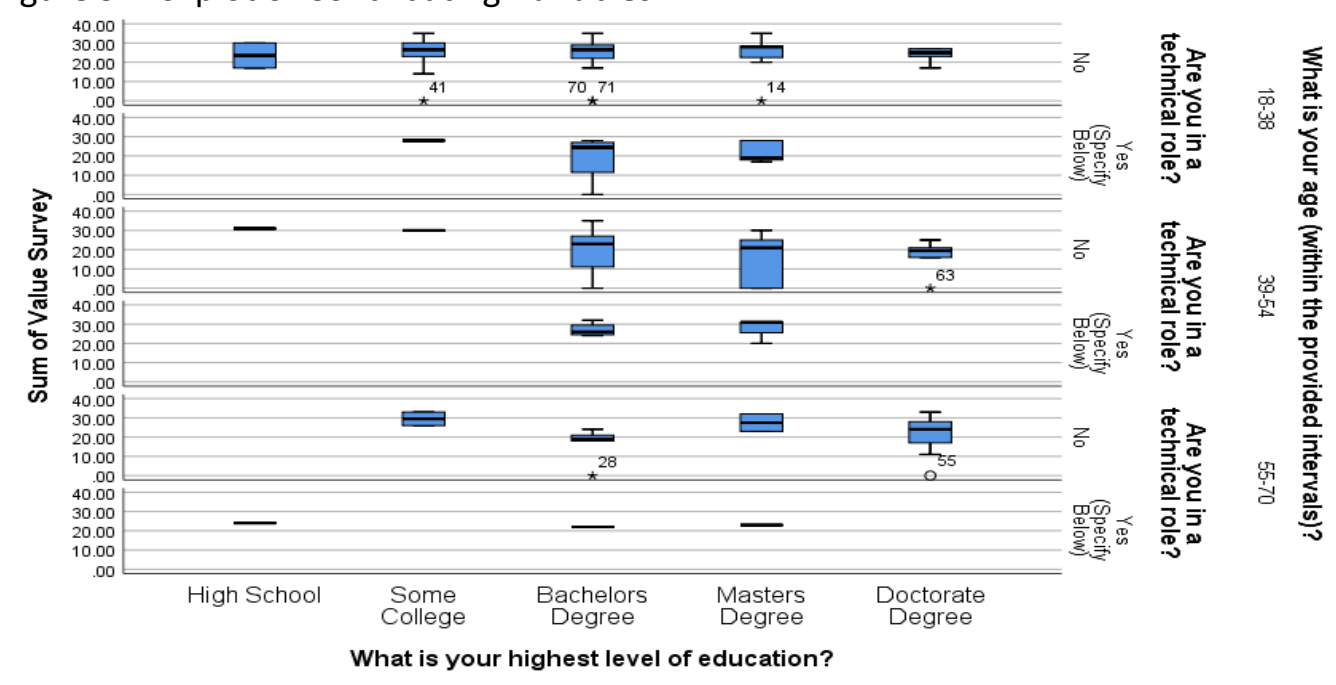

Note - Age Range represents Generations found few people that classified themselves as technicians $(n=17)$, yet Figure 8 does seem to indicate differences (although not statistically significant) between those with and without a technical background. In previous studies, employees identifying themselves as in a technical role did perceive Innovation and Value differently.

There is also a difference between the 2014 and 2019 studies in that generational differences remain (See Figures 6, 9). The 2014 study produced three factors with a similarity Figure 10: Factor Analysis - AONE Value Statements of explained variation (69\%) (Figure 10) and a reliability coefficient (Cronbach alpha) .70.

\begin{tabular}{|c|c|c|c|c|c|c|c|c|c|}
\hline \multicolumn{10}{|c|}{ Total Variance Explained } \\
\hline \multirow[b]{2}{*}{ Component } & \multicolumn{3}{|c|}{ Initial Eigenvalues } & \multicolumn{3}{|c|}{ Extraction Sums of Squared Loadings } & \multicolumn{3}{|c|}{ Rotation Sums of Squared Loadings } \\
\hline & Total & $\%$ of Variance & Cumulative $\%$ & Total & $\%$ of Variance & Cumulative $\%$ & Total & $\%$ of Variance & Cumulative $\%$ \\
\hline 1 & 2.573 & 36.756 & 36.756 & 2.573 & 36.756 & 36.756 & 2.244 & 32.056 & 32.056 \\
\hline 2 & 1.155 & 16.503 & 53.259 & 1.155 & 16.503 & 53.259 & 1.458 & 20.832 & 52.888 \\
\hline 3 & 1.091 & 15.589 & 68.848 & 1.091 & 15.589 & 68.848 & 1.117 & 15.961 & 68.848 \\
\hline 4 & .793 & 11.331 & 80.179 & & & & & & \\
\hline 5 & .665 & 9.502 & 89.681 & & & & & & \\
\hline 6 & .517 & 7.386 & 97.066 & & & & & & \\
\hline 7 & .205 & 2.934 & 100.000 & & & & & & \\
\hline
\end{tabular}

Box's Test of the Equality of Covariance Matrices tested to be insignificant ( $p$-value=.256), indicating consistency among the responses. The MANOVA tests indicate a significant interaction 
between age and education. Both generational differences and education achieved are significant when measuring innovation perceptions but not value.

\section{SUMMARY OF FINDINGS}

Innovation must add value to meet customer's unique needs. Approximately 1500 of the Innovation Perception Surveys have been analyzed since 2013. These analyses suggest that generational differences play a significant role in how innovation is perceived. Secondly, education is essential, and when sampled, technical individuals score considerably higher than non-technical individuals. However, when using a highly technical and professional group as the Association on Nursing Executives (AONE), the group's homogeneity impacted the results. Results varied again when using a random group of MBA students who perceived innovation from a distinctly different perspective. With this group, only the New category was distinguishable from improvement or change. The results continue to confirm the Zhuang $(1995 ; 1999)$ conclusion that innovation is perceived uniquely by individuals.

For this paper, the primary emphasis was on evaluating the "Value of Innovation." The 2019 Survey factored to one dimension, the 2014 study three dimensions. All other studies have just one factor. What is different between the two samples is the 2019 Values survey involved MBA students from several countries, the students are either Gen X or millennials, whereas the AONE survey involved several different generations groups, most with advanced degrees. The study's result confirms the need to market (sell) innovation to each generation differently. One size does not fit all! Innovation, as understood by the sample of individuals in an innovation-intensive industry, is a multi-dimensional construct. The data identified three or four distinct dimensions of innovation. The disconnect between how a concept is understood and how it is applied (or defined) causes problems. Realizing that innovation begins at the human level is critical for success. If everyone in an organization perceives innovation differently, and no alignment of perceptions occurs, innovation efforts will produce little or no success.

\section{LIMITATIONS}

The fact that the sample was diverse may be why some divergence between the original study and this iteration. The expectation was for most respondents (non-technical personnel) to not have a refined vision of understanding innovation. The two groups shared much in common. The results are not transferable to all individuals but would be familiar to those who experience innovation on a more frequent basis.

\section{RECOMMENDATIONS}

The authors continue to recommend additional research on understanding the value of innovation from a more complex perspective. Now it is time to examine how the alignment varies (and agrees at times) between the generational cohorts and technical awareness and practice. These can be further refined to a profile for each group that should be of interest to designers, developers, marketers, and researchers. Each group's profile would facilitate a more focused approach and a change from the current process that calls everything innovative and has little meaning to each group.

\section{APPENDIX A}

Survey Statements - Agreement Likert Scale

Strongly Disagree (1) Disagree (2) Neither Disagree nor Agree (3) Agree (4), Strongly Agree (5)

\section{Innovation Assessment Survey}

a - Inventing something entirely new

$b$ - Generating new ideas only 
c- Improve something that already exists

$\mathrm{d}$ - Following the market leader

e - Attracting Innovative people

$\mathrm{f}-$ Performing an existing task in a new way

$\mathrm{g}$ - Implementing new ideas

$\mathrm{h}$ - Adopting something that has been tried elsewhere

$\mathrm{i}$-Seeing something from a different perspective

$\mathrm{j}$ - Introducing Changes

\section{Value Survey}
a. How novel it is
b. How many people it involves
c. How long it takes
d. How much it costs
e. How significantly it improves the organization's profitability
f. How advanced the technology it applies to
g. The extent of change it entails

\section{REFERENCES}

Baregheh, A., Rowley, J., \& Sambrook, S. (2009). Towards a multidisciplinary definition of Innovation. Management Decision, 47(8), 1323-1339.

Bowersox, D. J., Closs, D. J., Cooper, M. B., \& Bowersox, J. C. (2013). Supply chain logistics management, $4^{\text {th }}$ edition. McGraw Hill, New York, NY 10020.

Buisson, B., \& Silberzahn, P. (2010). Blue ocean or fast-second innovation? A four-breakthrough model to explain successful market domination. International Journal of Innovation Management, 14 (3), 359-378. doi:10.1142/S1363919610002684.

Buttle, F., \& Maklan, S. (2019). Customer relationship management: concepts and technologies. Routledge.

Caraballo, E., \& McLaughlin, G. (2012). Individual perceptions of Innovation: A multi-dimensional construct, Journal of Business and Economic Research, 10(10), pp 553-568.

Chesbrough, H., Lettl, C., \& Ritter, T. (2018). Value creation and value capture in open innovation. Journal of Product Innovation Management, 35(6), 930-938.

Churchill, G. (1979). A paradigm for developing better measures of marketing constructs. Journal of Market Research, 16 (1), 64-73.

Crawford, F., \& Mathews, R. (2007). The myth of excellence: Why great companies never try to be the best at everything. Crown Business.

deWaal, A., Maritz, A., \& Shieh, C. (2010). Managing Innovation: A typology of theories practiced-based applications for New Zealand firms, International Journal of Innovation Organization. 3(2), 35-57.

Drucker, P. F. (2007). Management challenges for the 21st century. Routledge.

Flight, R., Allaway, A., Kim, W., \& D'Souza, G. (2011). A study of perceived innovation

Gee, V. \& Gee, S. (2011). Business improvement creates a culture of change and innovation. Journal for Quality and Participation, 34, 3, pp. 30-33.

Hair, J., Anderson, R., Tatham, R. and Black, W. (1995), Multivariate Data Analysis: Fourth

Hansen, M. T., \& Birkinshaw, J. (2007). The innovation value chain. Harvard business

review, 85(6), 121Healthcare, Boca Raton: CRC Press. https://www.ideatovalue.com/inno/nickskillicorn/2016/03/innovation-15-experts-shareinnovation-definition/

Kim, W. C. (2005). Blue ocean strategy: from theory to practice. California management review, 47(3), 105-121.

Kim, W. C., \& Maubourge, R. (1997). Value innovation. Havard Business Review, (1). 
Kowalkowski, C. (2011). Dynamics of value propositions: insights from service-dominant logic. European Journal of Marketing.

Kumar, V. (2014). Understanding Cultural Differences in Innovation: A Conceptual Framework and Future Research Directions. Journal of International Marketing, 22(3), 1-29.

Kwak, D. B., Yoffie, D. B., \& Kwak, M. (2001). Judo strategy: turning your competitors' strength to your advantage. Harvard Business Press.

Mangelsdorf, M. E. (2011). The user innovation revolution. MIT Sloan Management Review, 53(1), 1.

Massa, L., \& Tucci, C. L. (2013). Business model innovation. The Oxford Handbook of Innovation Management, Oxford University Press, Oxford, 420-441.

Matwiejczuk, R. (2013). Logistics potentials in business competitive advantage creation. Logforum, 9(4), 265-275.

Matzler, K., Bailom, F., Friedrich von den Eichen, S., \& Kohler, T. (2013). Business model innovation: coffee triumphs for Nespresso. Journal of Business Strategy, 34(2), 30-37.

McAdam, R., \& McClelland, J. (2002). Individual and team-based idea generation within innovation management: organisational and research agendas. European Journal of Innovation Management, 5 (2), 86-97.

McLaughlin, G. \& Caraballo, E. (2013). Chance or Choice: Unlocking Innovation

McLaughlin, G. \& Kennedy, W. (2016). Innovation Project Management Handbook, Boca Raton: CRC Press.

McLaughlin, G. \& Richins, S. (2014). Unlocking sustained innovation success in Healthcare. Boca Raton, FL: Taylor and Francis.

McLaughlin, H., McLaughlin, G., \& Presiosi, R.C. (2004). The relationship of learning orientation to organizational performance. Journal of Business and Economics Research, 2(4), 9-16.

Prahalad, C.K. (2012). Bottom of the Pyramid as a Source of Breakthrough Innovations. Journal of Product Innovation Management, 29 (1), 6-12.

Seybold, P. B., Marshak, R. T., \& Lewis, J. M. (2001). The customer revolution: How to thrive when customers are in control. Crown Business.

Simchi-Levi, D., Kaminsky, P., Simchi-Levi, E., \& Shankar, R. (2008). Designing and managing the supply chain: concepts, strategies and case studies. Tata McGraw-Hill Education.

Skillicorn, N. (2016). What is Innovation: 15 Experts given us their definition. Idea to Value. Retrieved from

Subbotina, N. (2015). Innovation in cultural sector - definition and typology. Zarzadzanie w Kulturze, 16(4), 379-IX. doi:http://dx.doi.org/10.4467/20843976ZK.15.025.3782 Success, Boca Raton: CRC Press.

Teague, P. (2008). P\&G is king of collaboration. Revista Purchasing, 137(9), 46.

Thompson, A., Strickland, A. J., \& Gamble, J. (2015). Crafting and executing strategy: Concepts and readings. McGraw-Hill Education.

Thompson, V. (1965). Bureaucracy and Innovation. Administrative Science Quarterly, 10, 1-20.

Vargo, S.L. and Lusch, R.F. (2008), "Service-dominant logic: continuing the evolution", Journal of the Academy of Marketing Science, Vol. 36 No. 1, pp. 1-10.

Viguerie, P., Smit, S., \& Baghai, M. (2008). The granularity of growth: how to identify the sources of growth and drive enduring company performance. John Wiley \& Sons.

Wang, S., Guidice, R., Tansky, J., \& Wang, Z. (2010). When R\&D spending is not enough: The critical role of culture when you really want to innovate. Human Resource Management, 49 (4) 767792.

Zhuang, L. (1995). Bridging the gap between technology and business strategy: A pilot study on the innovation process. Management Decision. 33 (8), 13-19.

Zhuang, L., Williamson, D., \& Carter, M. (1999). Innovate or liquidate - are all organizations convinced? A two-phased study into the innovation process. Management Decision, 37 (1), 57-71. 